\title{
Interval type-2 fuzzy logic controller design for distillation column process
}

\author{
Mohammed Y. Hassan, Sebal S. Ezzaten \\ Control and systems Engineering Department, University of Technology, Iraq
}

\begin{tabular}{l}
\hline \hline Article Info \\
\hline Article history: \\
Received Jul 24, 2018 \\
Revised May 25, 2019 \\
Accepted Jun 22, 2019 \\
\hline
\end{tabular}

Keyword:

Distillation

FLC

IT2

\begin{abstract}
Distillation columns are the most units used in oil refineries, and chemical factories. This is a very difficult process and non-linear. Therefore, the development of intelligent control systems for the columns of the distillation is very difficult. In this paper, an intelligent control strategy using Mamdani type Interval Type-2 PI Like Fuzzy Logic Controller (IT2FLC) is used. The controller consists of PD-Like FLC with integrated output. Kernek Mendel (KM) algorithm is used as the type reduction method for the IT2FLC. This controller is applied to control a continuous binary trays distillation column. The controller has three tunable gains to reach minimum overshoot, minimum error and minimum settling time at least variables can be controlled. The controller is a variable of the molar fraction of distillate and the reflex ratio is the manipulated variable. Integral Time Absolute Error (ITAE) is employed as an objective function to measure the improvement in time response where the error is between desired and output product composition. The performance of IT2FLC is compared with Type-1 PI Like FLC (T1FLC). The results of the simulations have shown that the project of IT2FLC works efficiently to no- disturbance and the effects of disturbance. Improve average is of $85 \%$ for a constant set-point without a disturbance and $80 \%$ with a disturbance. Furthermore, the average improvement for a step set-point is $53 \%$ without disturbance and $74 \%$ with disturbance. All results of the simulation confirmed the hardiness and control any consistent inaccurate with obvious advantages for the IT2FLC.
\end{abstract}

Copyright (C) 2019 Institute of Advanced Engineering and Science. All rights reserved.

\section{Corresponding Author:}

Mohammed Y. Hassan,

Control and systems Engineering Department,

University of Technology, Iraq.

Email:60003@uotechnology.edu.iq

\section{INTRODUCTION}

The columns of the distillation binary are likely the most of the controls in petroleum and chemical engineering. The dynamics of the variables thermo dynamic non ideality; size, uncertainty, and delay the measures of the composition put the control of procedures for the distillation with a challenging problems [1]. The auditors reported on fuzzy logic Type-1 that can be used successfully for a number of processes of non-linear and complex. Despite its wide popularity, it is shown in many scientific research cases the projects of the Type-1 FLC (T1FLC) have difficulties to minimize the impact of the uncertainties in the plant [2].

Therefore, the choice of the T1FLC does not necessarily the most favorable solution to the problem of control, whereas the best alternative is using Type-2 FLC (T2FLC) put the use of its fuzzy sets characterized by a consequence and, a larger number of parameters. T2FLC has been applied in many fields like vehicle nonlinear, suspension systems, robot mobile autonomous control, parallel mechanism of cable-driven, biochemical reactor control and inverted pendulum model.

Pratishthananda and Worapradya [3] was developed the control with a real-time for a column of a binary distillation using Type-1 PI Fuzzy Logic Controllers. A nonlinear control adaptive algorithm for 
a multi component batch distillation columns were developed by Jana and Murlidhar [4]. Canete et al. [5] applied a neurofuzzy adaptive control using soft sensors for continuous distillation column. Javadi and Hosseini [6] proposed the PI controller for a binary distillation column. Barceló-Rico et al. [7] realized the modeling and the control of a continuous distillation tower through fuzzy technique. A fuzzy model predictive control in multivariable control of distillation column was used by Sivakumar et al. [8] Al-Dunainawi and Abbod [9] performed three techniques of evolutionary algorithm as a tuner to fuzzy logic controller.

Distillation column, as previously described, is a high nonlinear, poorly-defined relationship between the inputs and outputs, characterized by uncertainty. Thus; using T1FLC did not achieve high accuracy in controlling a binary trays distillation column and faced difficulties in reducing the effect of disturbances and uncertainties in the distillation column continuous type.

The aim of this paper is to design IT2 PI-Like FLC for continuous distillation column (IT2FLC) to reach the set-point value for a distillate fraction $(\mathrm{Xd})$ with minimum overshoot, minimum error and minimum settling time despite the disturbance. Results will be compared with using Type-1 PI-Like FLC taking into account the variations in system parameters and disturbance.

\section{DISTILLATION COLUMN PROCESS AND MODEL}

It is known that distillation columns are the units that most used in oil refineries; chemical and petrochemical plants [9]. It is the unit the operation in automatic control must be studied. There are a lot of types of distillation columns like, continuous or batch, binary or multi component, packed or tray [1].

\subsection{Process description}

The distillation is a process in a liquid or vapor mixture of two or more components was separated into its fractions of required purity, by the application and removal of heat. Distillation column generally made up of trays of column. The distillation column consists of many trays, reboiler, condenser and a vertical column for the separation purpose.

The feed is the entry in the column. Distillation column is separated into two sections. They are rectification section and stripping section. Trays under the feed tray are called the section of stripping and trays above feed tray are called rectification section [10], Figure 1 Leaving the Condenser liquid is entered into the drum of the reflex. A part of this liquid column deals as a reflex and fall down by the trays. Finally, the fluid is withdrawn, drum as a purified product.

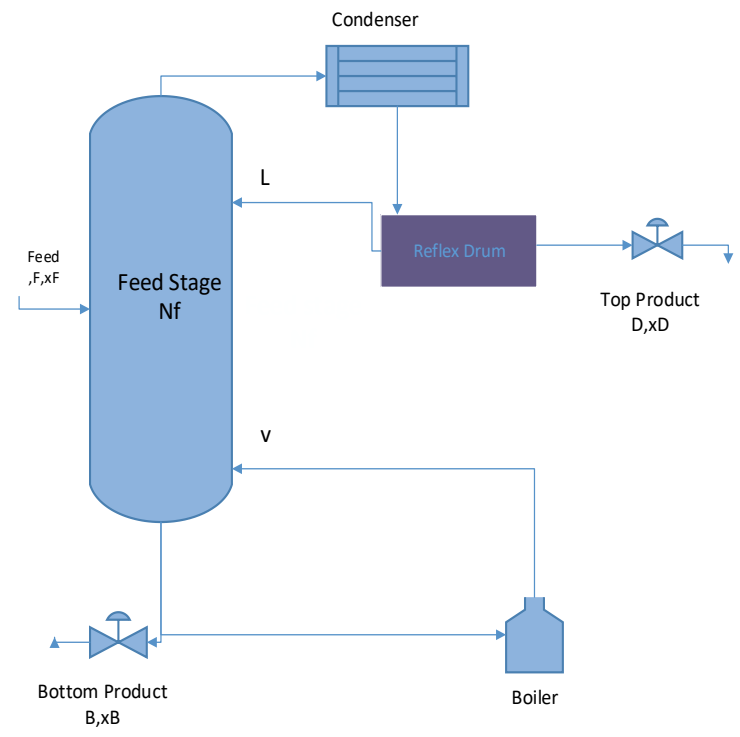

Figure 1. Schematic impersonation of a typical binary continuous distillation column [11]

\subsection{Mathematical model}

The nonlinear system is modeled with the mass balance and component balance equations. The model is simplified under the following assumptions [12]: 
- $\quad * * * * * * * * * * * /$ No chemical reactions occur.

- No change in (constant) pressure.

- Double (Binary) mixture.

- No change in a (constant) relative volatility.

- No vapor hold-up occurs in the trays.

- Perfect equilibrium and mixing for vapor-liquid on all stages.

- Perfect control level on reboiler and reflux drum.

The Mass balance equation for each stage is [1]:

- Consider stage $\mathrm{i}=\mathrm{N}+1, \mathrm{x}_{\mathrm{D}}=\mathrm{x}_{\mathrm{N}}+1$, where $\mathrm{N}$ is Number of stages, $\mathrm{x}_{\mathrm{D}}$ is the distillate liquid molar fraction, $\mathrm{x}_{\mathrm{N}}$ is Liquid concentration on $n^{\text {th }}$ stage is a Condenser stage and is represented as (1):

$$
\mathrm{M}_{\mathrm{D}} \frac{d x D}{d t}=\mathrm{V} \mathrm{y}_{\mathrm{i}-1}-\mathrm{L} \mathrm{x}_{\mathrm{D}}-\mathrm{D} \mathrm{x}_{\mathrm{D}}
$$

where $\mathrm{M}_{\mathrm{D}}$ is Condenser hold-up, $\mathrm{V}$ is Vapor flow rate, $\mathrm{y}_{\mathrm{i}}$ is Vapor molar fraction on $\mathrm{i}^{\text {th }}$ stage, $\mathrm{L}$ is Liquid flow rate and $\mathrm{D}$ is distillate flow rate.

- Stage $\mathrm{i}=\mathrm{NF}+1$ to $\mathrm{i}=\mathrm{N}$ : represents trays above feed tray where NF is the number of the feed tray and its equation is as follows (2):

$$
\mathrm{M}_{\mathrm{i}} \frac{d x i}{d t}=\mathrm{L} \mathrm{x}_{\mathrm{i}+1} \mathrm{~V} \mathrm{y}_{(\mathrm{i}-1)}-\mathrm{L} \mathrm{X}_{\mathrm{i}}-\mathrm{V} \mathrm{y}_{\mathrm{i}}
$$

where $\mathrm{M}_{\mathrm{i}}$ is Hold-up on $i^{\text {th }}$ stage and $\mathrm{X}_{\mathrm{i}}$ is Liquid molar fraction on $i^{\text {th }}$ stage.

- $\quad$ Stage $i=N F$ : represents feed tray and its equation is written as follows (3):

$$
\mathrm{Mi} \frac{d x i}{d t}=\mathrm{L} \mathrm{X}_{\mathrm{i}+1}+\mathrm{V} \mathrm{y}_{(\mathrm{i}-1)}-\mathrm{L} \mathrm{X}_{\mathrm{i}}-\mathrm{V} \mathrm{y}_{\mathrm{i}}+\mathrm{F} \mathrm{X}_{\mathrm{f}}
$$

where $\mathrm{F}$ is Feed flow rate and $\mathrm{X}_{\mathrm{f}}$ is Feed liquid molar fraction.

- Stages $i=2$ to $i=N F-1$ : represent the stages below the feed tray which are expressed as follows (4):

$$
\mathrm{Mi} \frac{d x i}{d t}=(\mathrm{L}+\mathrm{F}) \mathrm{x}_{\mathrm{i}+1}+\mathrm{V} \mathrm{y}_{(\mathrm{i}-1)}-\mathrm{L}(\mathrm{L}+\mathrm{F}) \mathrm{x}_{\mathrm{i}}-\mathrm{V} \mathrm{y}_{\mathrm{i}}
$$

- Stage $\mathrm{i}=1, \mathrm{x}_{\mathrm{B}}=\mathrm{x}_{1}$ : represents reboiler stage which is represented as follows (5):

$$
\mathrm{M}_{\mathrm{B}} \frac{d x B}{d t}=(\mathrm{L}+\mathrm{F}) \mathrm{x}_{\mathrm{i}+1}+\mathrm{V} \mathrm{y}_{\mathrm{B}}-\mathrm{B} \mathrm{x}_{\mathrm{B}}
$$

where $\mathrm{M}_{\mathrm{B}}$ is Reboiler hold-up, $\mathrm{x}_{\mathrm{B}}$ is Bottoms liquid molar fraction, $\mathrm{B}$ is Bottom flow rate, and $\mathrm{y}_{\mathrm{B}}$ is Vapor molar fraction on bottom stage.

- Vapor - liquid equilibrium relationship for each tray was represented as (6):

$$
\mathrm{y}=\frac{\alpha x i}{1+(\alpha-1) x i}
$$

where $\alpha$ is Relative volatility

- $\quad$ Reflux ratio is represented as (7):

$$
\mathrm{R}=\frac{L}{D}
$$

where $\mathrm{R}$ is Reflex ratio.

- Total reboiler mass balance is represented as (8):

$$
\mathrm{B}=\mathrm{F}-\mathrm{D}
$$

- $\quad$ Total condenser mass balance is represented as (9):

$$
\mathrm{D}=\frac{V}{R+1}
$$




\subsection{Modeling of the distillation column}

The equations of the model are encrypted by the MATLAB environment, s-script function is called by the block in a Simulink. The resolution ordinary differential equations are used ODE45. Figure 2 shows the model Simulink of continuous type distillation column from (1 to 9).

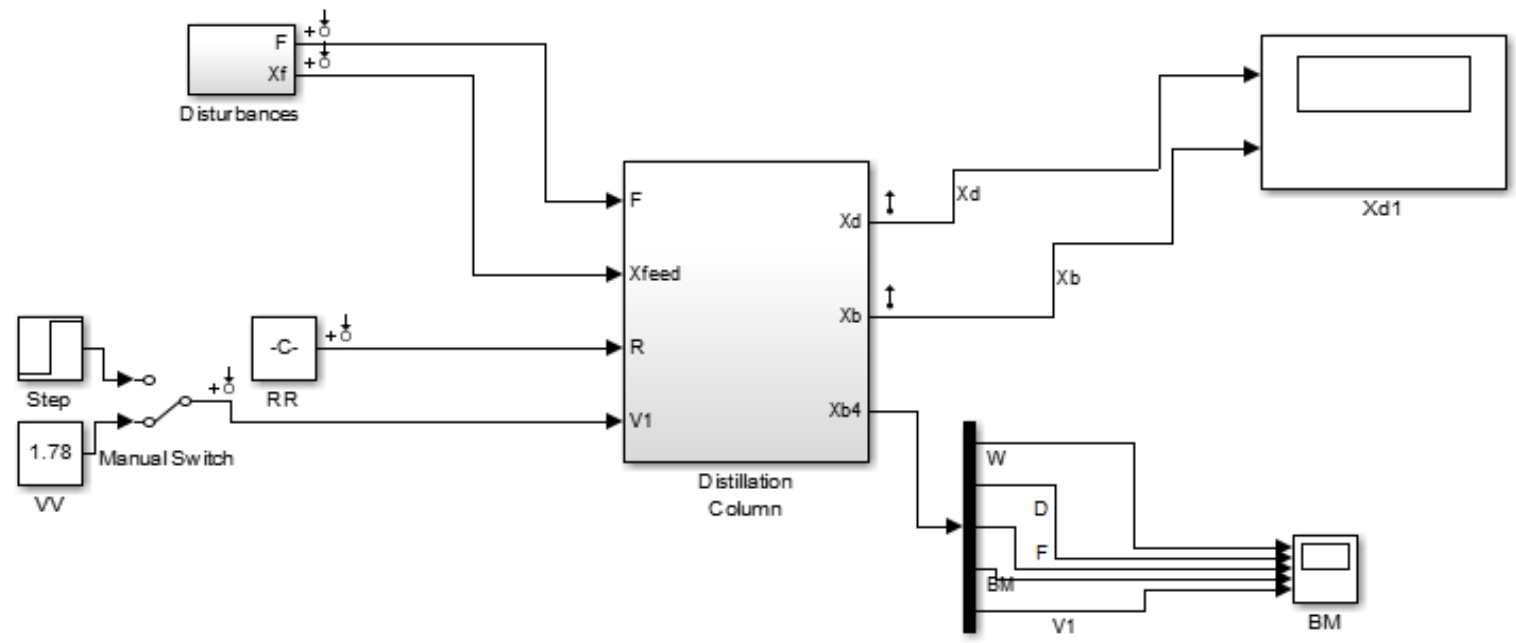

Figure 2. Model of continuous type distillation column (1-9)

Moreover, simulation model of the Distillation Column block is shown in Figure 3.

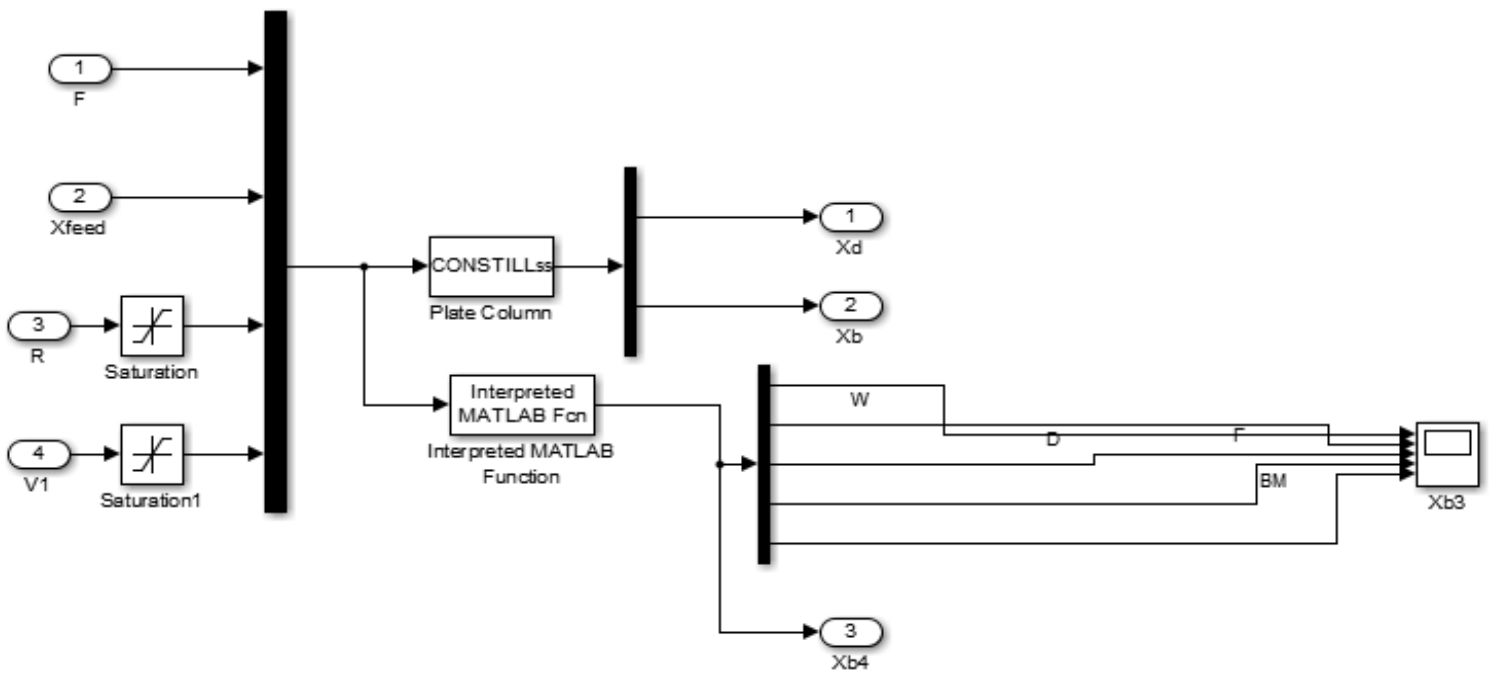

Figure 3. Simulink model of distillation column block (1-5)

where the block CONSTILLss in the Simulink of distillation column is s-function that contains the program which describes equations (1 to 5).

\subsubsection{Simulation response of open loop distillation column}

The simulation was performed, to ensure compliance with the dynamic working in the operation, whereby the parameters are listed in the Table 1 . The model has a non-linear reaction (response). Figure 4 shows dynamic response with the change in the reflex ratio (RR) as $+10 \%$ and $-10 \%$, where the nominal value of $R R$ is 2.56 [1]. 
Table 1. Parameters of distillation column model [1]

\begin{tabular}{cccc}
\hline Symbol & Typical value and unit & Symbol & values and unit \\
\hline$M_{B}$ & $0.5 \mathrm{kmol}$ & $\mathrm{F}$ & $1 \mathrm{kmol} / \mathrm{h}$ \\
$M_{D}$ & $0.5 \mathrm{kmol}$ & $\alpha$ & 2 \\
$M_{i}$ & $0.5 \mathrm{kmol}$ & $R R$ & 2.56 \\
$\mathrm{~V}$ & $1.78 \mathrm{kmol} / \mathrm{h}$ & $\mathrm{N}$ & 20 \\
$\mathrm{~L}$ & $1.28 \mathrm{kmol} / \mathrm{h}$ & $\mathrm{NF}$ & 11 \\
$\mathrm{D}$ & $0.5 \mathrm{kmol} / \mathrm{h}$ & $X_{F}$ & 0.5 \\
$\mathrm{~B}$ & $0.5 \mathrm{kmol} / \mathrm{h}$ & $X_{D}$ & 0.98 \\
\hline
\end{tabular}

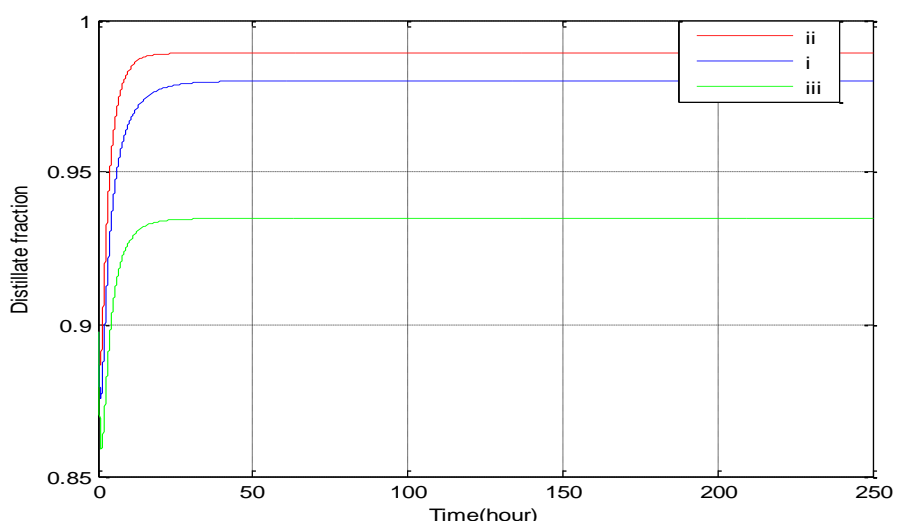

Figure 4. Dynamic response to the change in the reflex ratio (RR) (i) Response in the nominal value (Blue line), (ii) Response at $+10 \%$ in $\mathrm{R}(\mathrm{Red}$ line),

(iii) Response at $-10 \%$ in $\mathrm{R}$ (Yellow line)

\section{DESIGN OF THE PROPOSED CONTROLLER}

In the following section, the details of designing IT2 PI-Like FLC are explained.

\subsection{Design of IT2 PI-Like FLC (IT2FLC)}

The concept of T2FLC was proposed by Zadeh at 1975 as a statement of Type-1 FLC. Fuzzy sets function of the memberships are included in the Footprint Of Uncertainty (FOU), as shown in Figure 5. They are capable of modeling and handling the uncertainties, nonlinearities and linguistic associated with the inputs and output of FLC by modeling them and minimizing their effect. Therefore, IT2FLC is used instead of the T1FLC. IT2 fuzzy sets are extensions of the classical fuzzy sets that add an extra degree of freedom to entitle an uncertainty factor in the system but they are not easy compared with Type-1 FLC [13].

In this paper, IT2 PI like FLC of Mamdani type is designed with seven inputs-output triangular shaped memberships. The universe of discourse range is within $[-1$ to 1] for each input and output. The forms of MFs are shown in Figure 6. Centroid is the method that is selected for the defuzzification technique. The Rule-base of a proposed IT2FLC is shown in Table 2. KM algorithm is used to implement the type reduction method of the IT2FLC. The inputs and output gains of the controller with the rules were tuned to reach the best response to reach minimum overshoot, minimum settling time and minimum error in distillate molar fraction. The features of using Mamdani type are: it is my thought, it suits human input and it is commonly accepted.

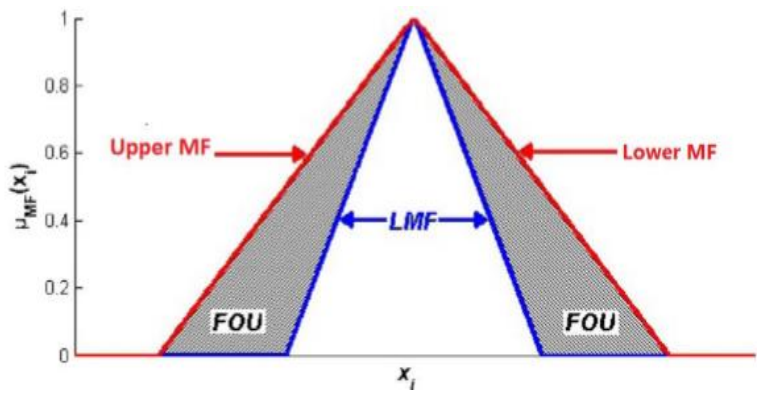

Figure 5. IT2 membership function structure [14]

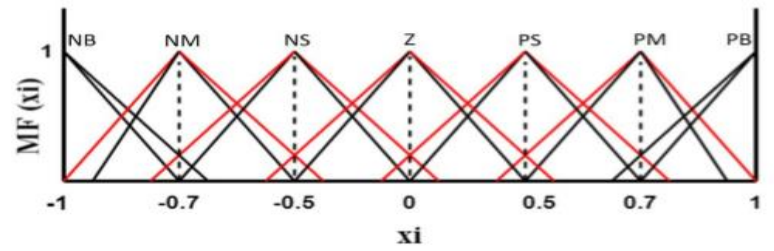

Figure 6. Input/Output MFs

Interval type-2 fuzzy logic controller design for distillation column process (Mohammed Y. Hassan) 


\begin{tabular}{cccccccc}
\multicolumn{7}{c}{ Table 2. Rule base of IT2FLC } \\
\hline e/ $\Delta$ e & NB & NM & NS & Z & PS & PM & PB \\
\hline NB & NB & NB & NB & NB & NM & NS & Z \\
NM & NB & NB & NB & NM & NS & Z & PS \\
NS & NB & NB & NM & NS & Z & PS & PM \\
Z & NB & NM & NS & Z & PS & PM & PB \\
PS & NM & NS & Z & PS & PM & PB & PB \\
PM & NS & Z & PS & PM & PB & PB & PB \\
PM & Z & PS & PM & PB & PB & PB & PB \\
\hline
\end{tabular}

A PI-like IT2FLC probably employed to serve as a PD such as IT2FLC. As shown in (10) shows a PD controller equation results in a position form, however (11) shows a PI controller [15].

$$
\begin{aligned}
& u_{D}(k)=K P e(k)+K D \Delta e(k) \\
& R R(k)=K o u t .(u I o(k)+u D(k))
\end{aligned}
$$

where $e(k)$ is a signal of sampled error, $\Delta e(k)$ is the sampled error signal rate change, index $\mathrm{k}$ represents the present sampling instant, $R R(k)$ is a control action, Kout is an output gain, $u I o(k)$ is the previous an control action and $u_{D}(k)$ is derivative control action.

\subsection{Design of the controller logic inaccurate type 1 (T1FLC)}

This article describes a Mamdani T1 PI Like FLC [1] is proposed as a comparison with IT2FLC where it should with two inputs and one output. The entries are going through a process of fuzzification with (5) membership. The trapezoidal membership was selected in the extremes and triangular membership in the middle and the defuzzification selected as the method is Centroid. More details can be found in the reference 1 .

\section{RESULTS AND DISCUSSION}

The controlled system is tested according to the following scenarios:

- Constant Distillate fraction set-point (0.98)

- Constant Distillate fraction set-point (0.98) with disturbance

- Step Distillate fraction Set-point

- Step Distillate fraction Set-point with disturbance

The Distillate fraction (XD) set-point is selected from a Table 1 as a purity of $98 \%$, the time of the simulation is 250 hours and the function of the cost used for the evaluation of the performance of the control is ITAE:

$$
\mathrm{J}=250 \int_{0}^{250}|e| d t
$$

The applied disturbance is the Feed flow rate $(\mathrm{F})$ and Feed liquid molar fraction XF [1], as shown in the Figure 7. The feed flow rate is represented as a Sine wave oscillation with low frequency and the Feed liquid molar fraction is represented as a smooth square wave with high frequency.

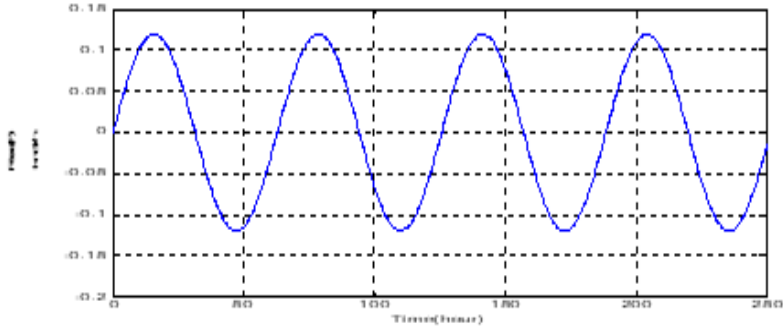

(a) Feed flow rate

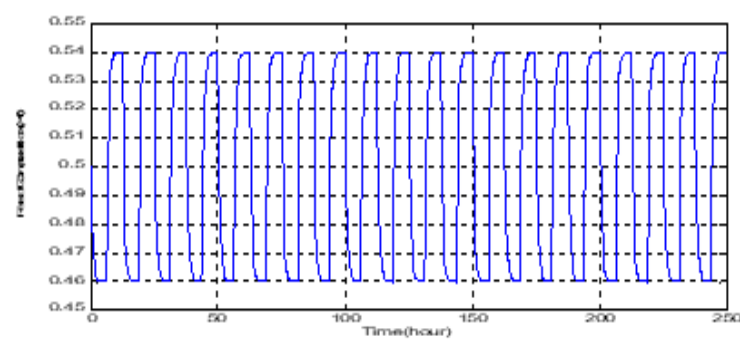

(b) Feed liquid molar fraction

Figure 7. Disturbances on the entire feed of the distillation column: (a) Feed flow rate (b) Feed liquid molar fraction 
The simulation of a closed loop for a distillation process using IT2FLC is shown in Figure 8 and the simulation of the closed loop for a distillation column process using IT1FLC is shown in Figure 9.

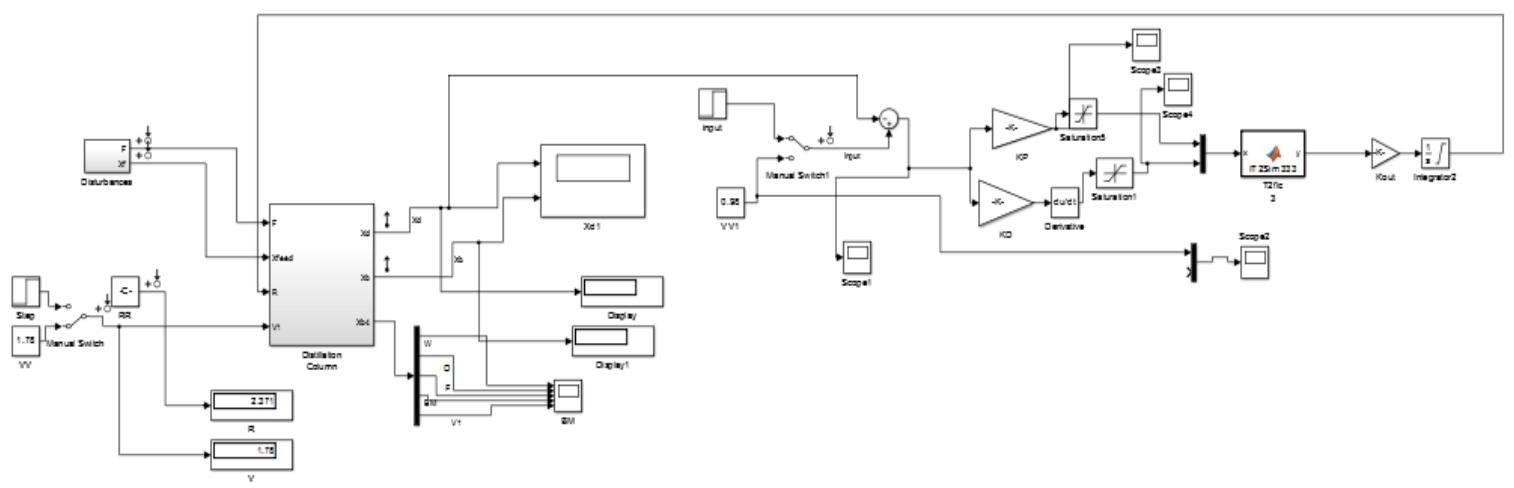

Figure 8. Closed loop system for a distillation column process using IT2FLC

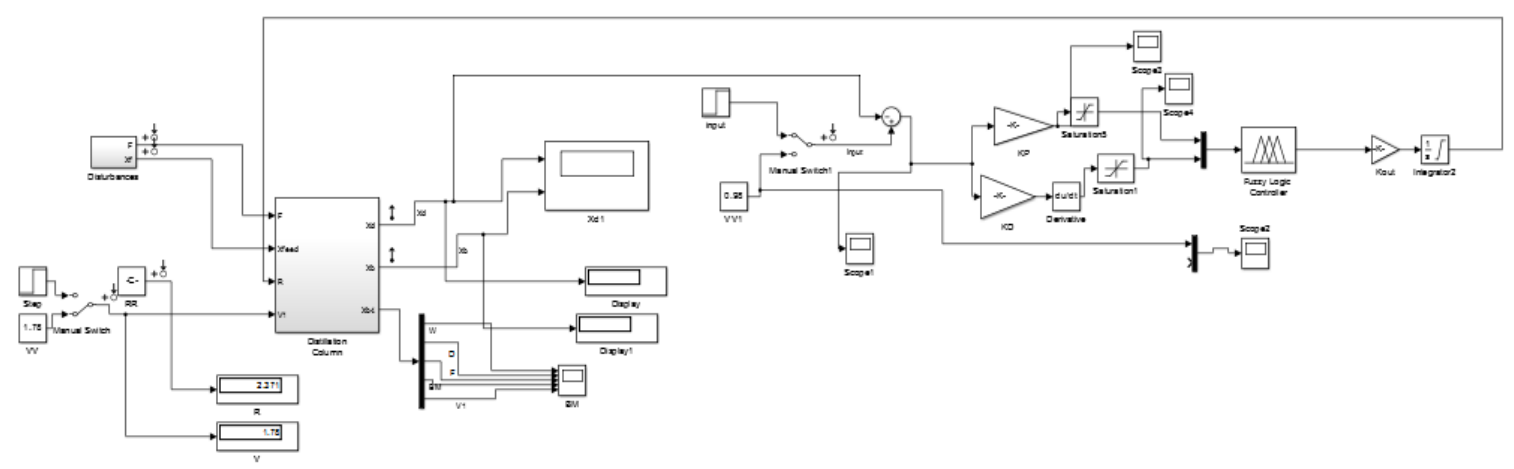

Figure 9. Closed loop system for a distillation column process using IT1FLC

The gains of the proportional control (KP), Derivative control (KD) and the output gain (Kout) are tuned manually for both controllers to reach the best time response as shown in Table 3 then the simulation response for the $\mathrm{Xd}$ concentration in both constant set-point and step set-point with disturbance and without disturbance for a Type-1 FLC are shown in Figure 10 and Figure 11 respectively and for an IT2FLC are shown in Figure 12 and Figure 13 respectively.

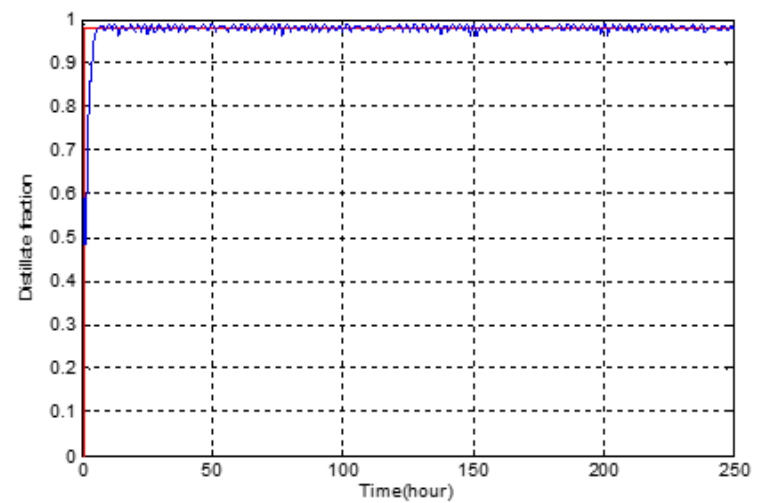

(a) Step set-point only

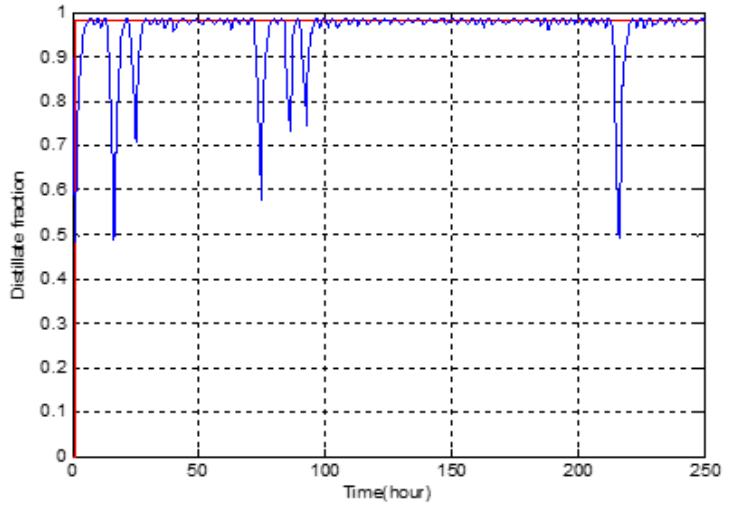

(b) Step set-point with disturbance

Figure 11. Time trajectory response of the system Xd consideration with fuzzy Type-1 for (a) Step Set-point only (b) Step Set-point with disturbance 
Table 3. Tuned gains for IT2LC

\begin{tabular}{ccccc}
\hline Types & $\begin{array}{c}\text { PI-Like IT2FLC } \\
\text { With constant set- } \\
\text { point only }\end{array}$ & $\begin{array}{c}\text { PI-Like IT2FLC } \\
\text { With constant set-point and } \\
\text { disturbance }\end{array}$ & $\begin{array}{c}\text { PI-Like IT2FLC } \\
\text { With step set- } \\
\text { point only }\end{array}$ & $\begin{array}{c}\text { PI-Like IT2FLC } \\
\text { With step set-point } \\
\text { and disturbance }\end{array}$ \\
\hline KP & 5 & 17.5 & 5 & 8.179 \\
KD & 5 & 9.98 & 5 & 3.4197 \\
$\mathrm{Ku}$ & 10 & 9.8 & 30 & 8.9 \\
\hline
\end{tabular}

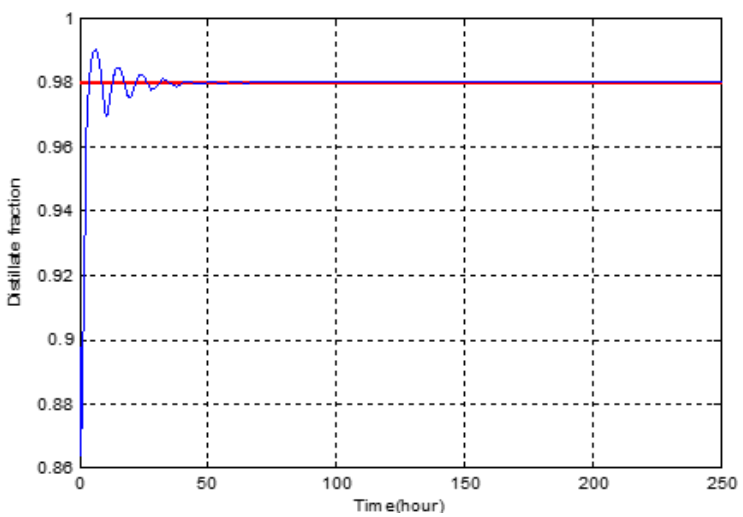

(a) Constant set-point only

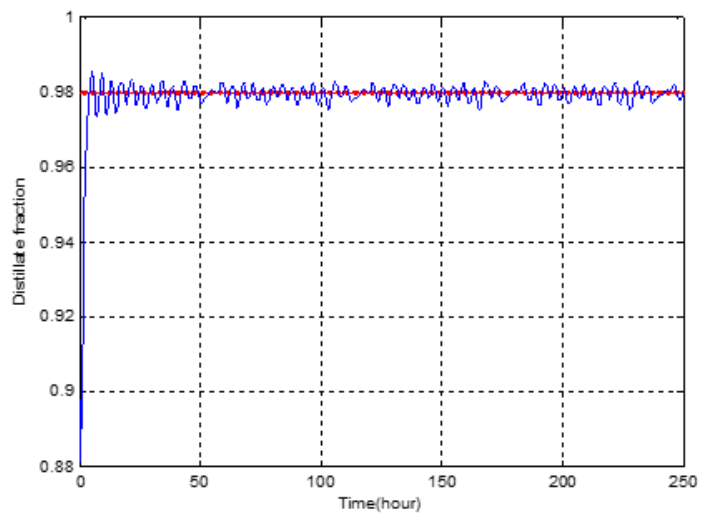

(b) Constant set-point with disturbance

Figure 12 . Time trajectory response of the system Xd consideration with fuzzy Type-2 for (a) Constant setpoint only (b) Constant set-point with disturbance

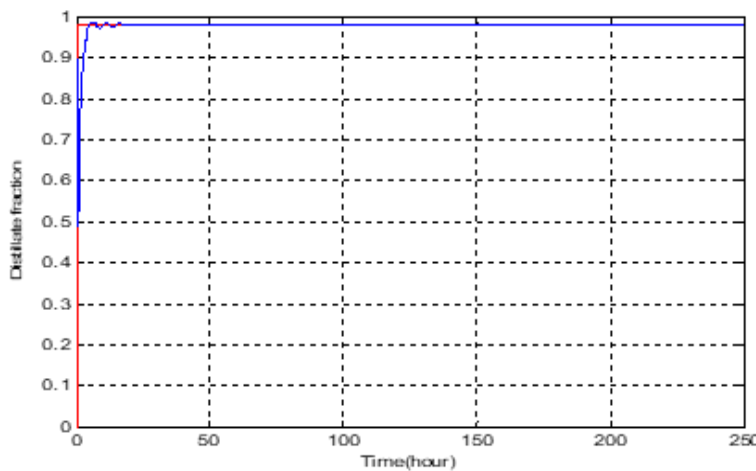

(a) Step Set-point only

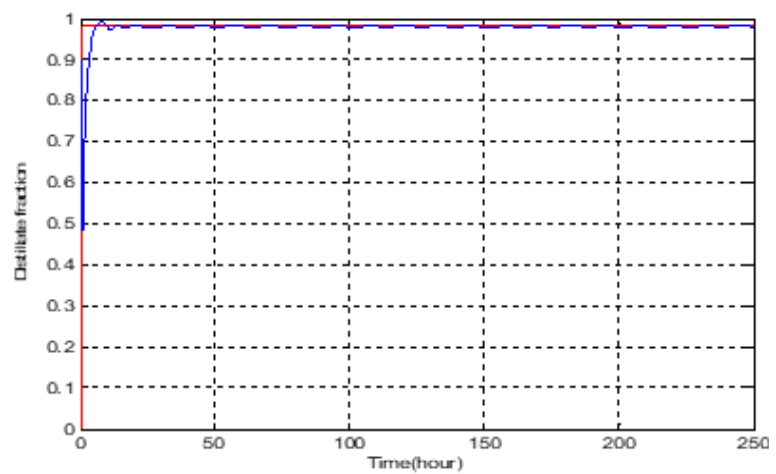

(b) Step Set-point with disturbance

Figure 13. Time trajectory response of the system Xd consideration with fuzzy Type-2 (a) Step set-point only (b) Step set-point with disturbance

By applying 12, the percentage of enhancement between the IT2FLC compared with IT1FLC for different cases are listed in Table 4.

Table 4. Percentage of enhancement between the IT2FLC compared with T1FLC

\begin{tabular}{lcccc}
\hline \multicolumn{1}{c}{ Controller } & $\begin{array}{c}\text { Constant } \\
\text { Set-point }\end{array}$ & $\begin{array}{c}\text { Step Set- } \\
\text { point }\end{array}$ & $\begin{array}{c}\text { percentage of enhan-cement } \\
\text { for constant Set-point }\end{array}$ & $\begin{array}{c}\text { Percentage of } \\
\text { enhancement Step input }\end{array}$ \\
\hline Type-2 & 76.23 & 286 & $\sim 85 \%$ & $\sim 53 \%$ \\
Type-2 with disturbance & 141.1 & 470.6 & $\sim 80 \%$ & $\sim 74 \%$ \\
Type-1 & 506.8 & 604 & & \\
Type-1 with disturbance & 737.3 & 1831 & & \\
\hline
\end{tabular}




\section{CONCLUSION}

The application of IT2 PI-Like FLC to the nonlinear dynamical model of a continuous type distillation column demonstrates the effectiveness in reaching a top control performance and allowing a faster and exact control of the process. The disturbance rejection and set point tracking is done with less amount of overshoot as a compared with using Type-1 PI-Like FLC. Simulations carried out, showed an average improvement measured using ITAE of $85 \%$ for a constant set-point without disturbance and $80 \%$ with a disturbance, for a step set-point the improvement is $53 \%$ without disturbance and $74 \%$ with disturbance.

\section{REFERENCES}

[1] S. Diaz, J. R. Perez-Correa, A. Cipriano and M. Fernandez "Intelligent Control Applications on a Binary Distillation Column," IEEE International Conference de la Association Chilena de Control Automatic, Talca, Chile, 19-21 Oct. 2016.

[2] K. Worapradya and S. Pratishthananda "Real Time Control of a Binary Distillation Column using HGA Fuzzy Supervisory PI Controllers," Tencon., pp. 814-818, 2005.

[3] G. M. Murlidhar and A. K. Jana "Nonlinear Adaptive Control Algorithm for a Multicomponent Batch Distillation Column," Chemical Engineering Science 62, pp. 111-1124, 2007.

[4] J. Fernandez da Canete, P. Saz-Orozco and S. Gonzalez-Perez. "Application of Adaptive Neuro Fuzzy Control using Soft Sensors to Continuous Distillation," Computer Aided Chemical Engineering 25, pp. 465-470, 2008.

[5] S. Javadi and J. Hosseini "Control of a Binary Distillation Column using PI Controller," 9th WSEAS International Conference on Signal Processing Computational Geometry and Artificial Vision, World Scientific and Engineering Academy and Society(WSEAS), pp. 145-152, 2009.

[6] F. Barcelo-Rico, J. M. Gozalvez-Zafrilla and J. L. Diez "Modeling and control of a continuous distillation tower through fuzzy techniques," Chemical Engineering Research and Design 89, pp. 107-115, 2011.

[7] R. Sivakumar, S. Manic, V. Nerthiga, R. Akila and K. Balu "Application of Fuzzy Model Predictive Control in Multivariable Control of Distillation Column," International Journal of Chemical Engineering and Applications 1, pp. 38-42, 2010.

[8] Y. AL-Dunainawi and M. F. Abbod "Evolutionary Based Optimization of Multivariable fuzzy control System of a Binary Distillation Column," International conference on computer Modeling and Simulation, UK, pp. 127-132, 2016.

[9] M. Sharmila and V. Mangaryarkarasi "Modeling and Control of Binary Distillation Column," Electrical, Electronic, and Instrumentation Engineering, an ISO Certified Organization, Vol. 3, pp. 105-111, 2014.

[10] Y. AL. Dunainawi and M. F. Abbod "PSO-PD Fuzzy Control of Distillation Column," SAI Intelligent System Conference, London, UK, pp. 554-558, 2015.

[11] A. George and R. M. Francis "Model Reference Adaptive Control of Binary Distillation Column Composition using MIT Adaptive Mechanism," Engineering Research and Technology 4, pp. 555-558, 2015.

[12] H. Ying, "Fuzzy Control and Modeling, Analytical Foundations and Applications," Wiely-IEEE Press, USA, 2000.

[13] M. B. Ozek and Z. H. Akpolat "A Software Tool Type-2 Fuzzy Logic Toolbox," Comput-APPI-Eng-Edu, Vol. 16, No. 2, pp. 137-146, 2008.

[14] Bartolomeo Cosenza "Control of a Distillation Column by Type 2 and Type 1 Fuzzy Logic PID Controller," Journal of Process Controller 24 , pp. 475-484, 2014.

[15] Mohammed Y. Hassan and Saif Faris Abulhail "Design of FPGA Based Interval Type2 Fuzzy Logic Controller," M. Sc. thesis, Control and System Engineering Department at University of Technology, Iraq, 2017. 